\title{
Research on Micro-information Platform of Information Literacy Education in the Era of "Internet+"
}

\author{
Bo Zhou \\ Hechi University, Yizhou City, Guangxi, China \\ zhoubo1114@163.com
}

Keywords: Internet; Micro information; E-Learning; Information literacy

\begin{abstract}
The information literacy education in the era of Internet+ is formed by such factors as knowledge fragmentation, time fragmentation and approach fragmentation. Analyzing the necessities of micro services in university library, the study focuses on that the education of the information literacy needs to discard the education concept of the centralized system, uses short and accurate education content and chooses open learning platform. By studying the features of micro-information and its technical foundation, the development of micro-course and the practice of information services in the library, the micro platform of information literacy education is constructed.
\end{abstract}

\section{Introduction}

The rapid pace of modern life enables the people to read more pieces of information in a relatively short time and the access to all kinds of information for Chinese young people has been experiencing the transition from traditional wired Internet access to the mobile Internet access. People can obtain such fragmental but concise micro-information as all kinds of APPs, micro-blogs, WeChat. Stepping into the era of micro-information, the popularity of such micro-information as Weibo, WeChat, micro film, animation, micro sites has made Chinese mobile Internet filled with possible explosion. With the popularity of such new emerging media as Weibo, WeChat and micro sites, information communication and consulting through the mobile Internet has been gradually accepted by the public. As the emergence of E-commerce like Taobao mall has changed the consumption pattern of Chinese, micro-information will also change the mode of social and economic development of China. Modern information technology, such as mobile Internet, cloud computing and big data, plays a supporting role in investigating new teaching mode and innovating new teaching methods for the libraries and supplies a good chance to improve library information services and information ability. Due to Online study and e-learning trends, traditional class room method are getting replaced [1]. Promotion of characteristics of information literacy education knowledge contents and rapid development of mobile learning bring information literacy education into miniaturization [2]. The libraries should emphasize how to make the use of all kinds of transmission modes to innovate and exploit library teaching methods. Meanwhile, because micro-information display can fully and quickly display service resources and enables the readers know how to make the use of the library resources the as soon as possible, it will help the libraries to extend services more effectively and improve the popularity of the library. The inquiry into the logic of formation in the perspective of Internet+ is propitious to find an innovation path of traditional information literacy education model $[3,4]$.

In the era of Internet+, the micro teaching mode has emerged and the fragmental social communication context will meet the demands of E-Learning. Micro-courses formally cater for the teaching and learning mode which becomes fragmented and microminiaturized, make information literacy education free from time and space constraints, and offer an opportunity for the university library to promote their information literacy education service [5,6]. The university libraries are with all kinds of information resources, but the uneven readers' information literacy and information ability makes all kinds of resources of the libraries not used fully, which causes the quality of the whole service of the libraries has improved slowly. And social core people acquire reference information through various mass media, so the promotional mode of the original professional 
literature resources in the library is hard for the library to attract the attention of many readers. Because the existing teaching methods are lacking of consideration for the students' personal needs, the interaction between the teachers and the students and the good quality of sharing teaching resources, the new mode of transmitting micro-information with low cost and high efficiency is needed to publicize the characteristic cultural information resources of the library, including using mobile terminal to improve various retrieval teaching, using micro-blogs to interact in real time, using the teaching of Micro-course to achieve personalized learning for a short period of time and using the Internet and mobile network platform combined with Micro-course teaching to enhance readers' information literacy to make the resources of the library used by the public fast and frequently [7]. They should draw lessons from the construction concept of MOOC and the features of Micro-course such as being short, interactive, easy to download and expand [8]. It uses the interaction between MOOC and the Micro-course to reflect its advantages in information literacy teaching and to enable the readers to learn how to learn and use the relevant information.

\section{Micro-information Aggregation Teaching}

The main feature of micro-information aggregation teaching is to combine the learning platform for mobile network with multiple micro-information with learning the course of the relevant information literacy as information retrieval. The concept of teaching promotion about micro-information aggregation education is using their unique way of information transmission in mobile network to build a diversified platform for micro-information aggregation teaching through gathering and integrating such micro-information elements as micro-blog, WeChat, micro-video, Micro-course. Meanwhile, it is the way of the flexible and changeable presentation of micro-information that can fully, conveniently and quickly show the rich information resources on the teaching platform and make the readers get the access to various information resources through the mobile intelligent devices and learn to use the rich information resources in the library at first time. It can improve the popularity and expand the influence of the library to promote the teaching of information literary for the readers and the college students through the platforms for the pluralistic micro-information teaching as micro-blog, WeChat, micro film, micro animation, micro website.

Micro-information Teaching Mode. The basic orientation of micro-teaching for college students' information literacy should be the gradual fragmentation of teaching resources, micro-service and flexible management. The students can have access to relevant professional literature information through the advanced micro-information platform. Meanwhile, they can acquire the retrieving information of the relevant library, service information and the corresponding resource information. The micro-information teaching platform will adjust the system from the perspective of components and fragmentation, adopting the advanced technology architecture and the components of construction mode and completing all kinds of the release of fragmental micro information. All kinds of micro information use the platform to manage the information resources and achieves the sharing of the micro information of library resources. The micro information shares on the information resource platform and creates the united foreign service and window to realize the micro promotion and fine management of information resources and services.

The Teaching Platform of Diversified Micro-information Gathering Portal. The teaching platform of diversified micro-information gathering portal is established with the development of innovative application of mobile system platforms like mobile Internet technology, android, IOS, WIN PHONE. The construction of the teaching platform of diversified micro-information gathering portal can make the $3 \mathrm{~W}$ portal and the platform of digital teaching based on $\mathrm{B} / \mathrm{S}$ architecture transplanted on the mobile intelligent terminals, achieving the goal that the existing websites and digital teaching platforms can be presented through the micro-platforms as APP client, WeChat public number, micro-blog at the mobile terminals. The platform of micro-information teaching will focus on the aggregation portal service of micro portal, micro function and micro service. The teaching platform of diversified micro-information gathering portal is the combination of mobile 
Internet construction, mobile APPS and mobile information service to realize the release of teaching resources at the mobile terminals. After the aggregation and transformation, it can be presented on the micro APP, micro-blog, WeChat in the readers' smart mobile terminals. With the release of such diversified information as micro-platform, micro-app, micro-blog, the platform can provide such micro-services to promote information literacy as information retrieval, information utilization, information processing at any time.

\section{Framework of Micro-information Platform}

The platform for micro-information of teaching should stress the basic knowledge, improve the curricular, strengthen the extracurricular, mainly learn by themselves and teach to arouse the students' passion for learning and fully explore the students' potentials to learn in order to provide the space and platform of micro-information learning for the students. In the process of teaching, the platform should combine the open the open educational thinking with scientific practices and the advantages of modern micro-class education with the advantage of flexible forms of micro-information, attaching great importance to the students' thinking style and exploratory practice, especially the combination of the exclusive study and coordinate practice. When planning the curriculum, it aims to improve the quality of information gathering, screening and applicating, taking it into the consideration that the students are characteristic of high adaptability in the mobile Internet society, strengthening the consciousness of self-learning and supporting to achieve effective learning in the form of various mobile media. In the process of teaching practice, the teaching content of micro-information should be constantly updated and enriched. Many forms of teaching means should be adopted and the attention should be paid to cultivating the students' ability to analyze, integrate information and to use skills, exploring the teaching mode of self-learning ability to improve the technical quality of students.

Mobile Network Teaching. By using such techniques as PHP, Apache, XML and FLASH for network teaching platform interactive design, the platform will achieve the teaching mode of classroom teaching with the combination of multimedia with online to make information retrieval, the main content of micro course, online simulation practice. It will present the learners micro video courseware in the forms of video, images and text as well as the process of retrieving the real-time dynamic network literature information resources to make the teaching and the practicing directly and vividly highlight the participation and interaction of the teaching process, significantly improve the real-time feedback of teaching effect.

Autonomous Learning and Testing. With the content of virtual classroom teaching of mobile multimedia forms and through constructing the waterfall streaming class and micro courseware database, the platform can guarantee that the students can self-learn on the Internet and learn, preview and review at other times with the purpose of constructing a modern teaching mode that mainly focuses on the learners' autonomous learning and exploratory learning to cultivate students' innovative and differentiated consciousness. By using such information technology application as streaming media, big data and cloud computing, mobile Internet, the platform can construct micro-teaching class adapting to cultivating applied talents information literacy, information literary investigation and test and test questionnaire to record, understand and self-test the students' learning situation at any time. In this way, the students can test by themselves, find out the problems and how to improve learning so that they can independently supervise and improve in the process of learning.

Course Resources Interacting. The platform will use the mature B/S mode to provide the connection and access to the resource base of micro-information, being able to make the platform for teaching display more interactive and real-time. The website of the platform for teaching micro-course links the free resources and makes the students grasp the knowledge in class and have the chance to learn micro-course material at home and abroad so as to achieve the common reserves of mobile Internet resources and the sharing of teaching information resources. Besides, the students should flexibly use the platform for teaching micro-information with real-time information 
communication function to make the teachers and the students communicate and interact in real time on the platform and support the teachers and the students to search and transfer the resources of micro-information teaching in the mobile Internet.

\section{Summary}

The platform of micro-information teaching makes full use of computer network technology and modern multimedia education technology to integrate information literacy teaching resources of college students, changing the tradition teaching form with the characteristic of being taught and explained mainly by the teacher into MOOC marked by learning and exploring by students themselves and converting the original classroom form into the form of micro-information curriculum based on mobile Internet platform. The platform allows students to link the platform for micro-information teaching to retrieve and practice and the platform for MOOC network teaching to learn and communicate through their own intelligent mobile equipment at any time and at any place. The platform allows the students to learn by themselves at flexible time and at free place with the fragmental but suitable education resources and finish their studies which was hard to realize in the past teaching with the limit of time and place. Through the formation of students' autonomous learning style and the development of self-learning ability, the students' basic literacy and information ability have been improved rapidly. Therefore, students should not be restricted by the classroom and the library and they should be able to learn and retrieve online at any time and at any place. Through the construction of micro-information platform and the practice of online teaching, the college students' information literacy curriculum will complete the training tasks for the cultivation of application-oriented talents more successfully.

\section{Acknowledgements}

The work reported in this paper was financially supported by the Scientific Research Fund of Instructional Software of Hechi University (grant no. 2015ER01). The writing committee would like to acknowledge Hechi University for its efforts in supplying laboratory and research instrument.

\section{References}

[1] P. Murali: International Journal of Scientific and Research Publications, Vol. 7 (2017) No.8, p.59-62.

[2] Y. Han: Library Development, (2016) No.8, p.61-65. (In Chinese)

[3] J.F. Zhou, G.F. Liu and Y.P. Sha: Library and Information Service, Vol. 60 (2016) No.1, p.19-25. (In Chinese)

[4] H.X. Jiao: Modern Information, Vol. 37 (2017) No.2, p.93-97. (In Chinese)

[5] J. Dong, X.W. Yu: Researches in Library Science, (2016) No.15, p.7-10. (In Chinese)

[6] T. S Wang, Q.L. Guo, Y. Qin and S.W. Yang: Sci-Tech Information Development \& Economy, (2015) No.18, p.29-32. (In Chinese)

[7] Y.W. Fan, R. Ni and T.Y. Feng: Journal of Library and Information Sciences in Agriculture, Vol. 29 (2017) No.5, p.125-126. (In Chinese)

[8] Y.P. Sha, J.F. Zhou and G.F. Liu: Library and Information Service, Vol. 59 (2015) No.15, p.68-72. (In Chinese) 